\title{
Preparation and Evaluation of Rosuvastatin Calcium Nanosuspension and Solid Dispersion Tablets by Wet Granulation and Direct Compression Techniques using Tamarind Gum as a Binder
}

\author{
S. ARJUN, S. KARTHIK, K. ARJUNAN, S. HARIHARAN ${ }^{1}$, P. SEENIVASAN² AND V. SANKAR*
}

Department of Pharmaceutics, ${ }^{1}$ Department of Pharmaceutical Chemistry, PSG College of Pharmacy, Coimbatore-641 004, 2Department of Pharmacy Practice, Faculty of Pharmacy, Sri Ramachandra Institute of Higher Education and Research, Chennai-600 116, India

Arjun et al.: Rosuvastatin Calcium Nanosuspension and Solid Dispersion Tablets

\begin{abstract}
The current investigation was attempted to enhance the solubility and dissolution of rosuvastatin calcium through nanosuspension and solid dispersion techniques using tamarind gum as a binder. Rosuvastatin calcium nanosuspension and solid dispersion were prepared using high shear homogenisation and melt fusion techniques, respectively. Various pre-compression tests were performed for the powder blends. Finally, tablets containing these nanosuspensions and solid dispersions were evaluated for various post compression quality control parameters. The nanosuspension had a particle size of $453.3 \pm 23.6 \mathrm{~nm}$ with a neutral surface charge. Using the lyophilised nanosuspensions and solid dispersion, tablets were prepared by wet granulation and direct compression techniques. The results of in vitro drug release studies in pH 6.8 buffer showed enhanced solubility and release of rosuvastatin calcium from the tablets containing nanosuspension and solid dispersion in $60 \mathrm{~min}$, when compared to the control tablets and a marketed tablet. Additionally, the property of tamarind gum to enhance the release of drug was also observed.
\end{abstract}

Key words: Nanosuspension, solid dispersion, tamarind gum, rosuvastatin calcium

Among the various routes of delivery available, the oral route is the most preferred route of administration, with advantages like high patient compliance and better pharmacokinetic profile ${ }^{[1]}$. Tablets constitute a major portion of drug delivery systems that are currently available in the market. Factors like economic feasibility, ease of manufacturing, patient compliance and lack of excipient toxicity render tablets as the most preferred form of drug delivery system ${ }^{[2]}$. Although the science of nanotechnology has achieved new heights for enhancing the bioavailability at the laboratory level, translating the product to tablets for oral administration remains the ultimate goal to cater patients in the clinic.

Solubility is one of the important factors required to achieve desired systematic concentration of a drug in systemic circulation for achieving the desired therapeutic response ${ }^{[3]}$. Low aqueous solubility is the major problem in formulation development of several new chemical entities ${ }^{[4]}$. Often, these poorly water soluble drugs need to be administered at high doses

*Address for correspondence

E-mail: sansunv@yahoo.co.in

January-February 2020 to achieve desired therapeutic plasma concentrations after oral administration ${ }^{[5]}$. A great number of new and possibly beneficial chemical entities do not have suitable pharmaceutical dosage forms because of their poor solubility and poor dissolution rates. The oral absorption of drugs is most often controlled by dissolution in the gastrointestinal tract ${ }^{[6]}$. Hence, an attempt was made using a model drug with poor solubility and dissolution. Rosuvastatin calcium (RC), a HMG-CoA reductase inhibitor, is widely used in the treatment of hyperlipidemia. $\mathrm{RC}$ promotes conversion of HMG-CoA to mevalonic acid by reducing the synthesis of cholesterol. However, RC has poor solubility and bioavailability $(20 \%)^{[7,8]}$. Of late, various kinds of

This is an open access article distributed under the terms of the Creative Commons Attribution-NonCommercial-ShareAlike 3.0 License, which allows others to remix, tweak, and build upon the work non-commercially, as long as the author is credited and the new creations are licensed under the identical terms

Accepted 10 November 2019 Revised 15 August 2019

Received 13 May 2019 Indian J Pharm Sci 2020;82(1):32-40 
formulations of RC such as self-nanoemulsifying drug delivery systems ${ }^{[7]}$, lipid nanoparticles ${ }^{[9]}$, nanolipospheres ${ }^{[10]}$, solid lipid nanoparticles ${ }^{[11]}$ and nanostructured lipid carriers ${ }^{[2]}$ have been developed to enhance the oral bioavailability of RC. However, solid dispersion and nanosuspension of RC (NRC) have not been evaluated. The present research work deals with the development of tablets using nanosuspension and solid dispersions of RC to enhance its solubility and dissolution.

Solid dispersions are one or more active ingredients dispersed in an inert carrier or matrix in solid state prepared by melting, dissolution in solvent, or meltingsolvent method ${ }^{[13,14]}$. Among the various approaches to improve solubility, the solid dispersion technique has often proved to be the most successful in improving the dissolution and bioavailability of poorly soluble drugs. Nanosuspensions, when compared to micron-sized counterparts, increase the solubility and dissolution of drugs due to enhanced surface area and reduced surface tension $^{[15,16]}$. Both solid dispersions and nanosuspensions will allow the drugs to remain in the amorphous form and help in the development of a stable formulation. These amorphous forms will immediately dissolve in the gastrointestinal tract and promote rapid absorption to enhance bioavailability.

Natural gums have advantages over synthetic materials because they are non-toxic, cheap, and easily available. Furthermore, they can be tailored for drug delivery applications. Many kinds of natural gums like acacia gum, tragacanth gum, guar gum and locust bean gum are widely used and categorized as safe for human consumption ${ }^{[17,18]}$. Tamarind gum is chemically a highly branched carbohydrate polymer. It can be obtained from the waste of tamarind kernels left after cooking. Tamarind gum has applications in paper, food, textile industry. Research in recent years explored the use of tamarind gum in pharmaceutical and cosmetic applications. The application of tamarind gum as a binder in the preparation of tablets has only been partially explored. Additionally, tamarind gum has been explored in the preparation of hydrogels, emulsifying agents, cosmetic preparations, and as a stabilizer in capsule preparation ${ }^{[19-21]}$. In this investigation an attempt was made to prepare NRC and solid dispersion of RC (DRC) to enhance the solubility and dissolution. Finally, tablets containing NRC or DRC were prepared using tamarind gum as a binder.

\section{MATERIALS AND METHODS}

RC was a gift sample from Strides Arcolab, Bangalore,
India. Sodium starch glycollate, talc, tribasic calcium phosphate and sodium lauryl sulphate were purchased from Loba Chemie Ltd., Mumbai, India. Mannitol and Pluronic F68 were purchased from HiMedia Limited, India. Lactose was purchased from SD Fine Chem Limited, India. Magnesium stearate was purchased from Otto Chemical Reagents, India.

\section{Extraction of tamarind gum:}

The tamarind seeds were collected from the fruits of the tree, Tamarindus indica. The outer covering of the seeds were removed and the white kernels $(20 \mathrm{~g})$ were crushed to obtain a fine powder. The powder was boiled for $1 \mathrm{~h}$ in 11 distilled water in a glass container to obtain a thick slurry. The obtained slurry was filtered and washed using absolute ethanol, isopropyl alcohol, and methanol and dried at $50^{\circ}$ in a hot air oven. The dried product was ground in a mortar with a pestle to get a fine powder of tamarind gum ${ }^{[22]}$. The gum powder was stored in an air tight container.

\section{Differential scanning calorimetry (DSC):}

DSC evaluation was performed to find out the nature of the formulations using a DSC instrument (Mettler Toledo). Typically, $4 \mathrm{mg}$ of sample was taken within a closed aluminium crucible and placed into a temperature controlled DSC cell and the temperature range was measured from 30 to $400^{\circ}$ and the heating rate was $20^{\circ} / \mathrm{min}$.

\section{Fourier-transform infrared (FTIR) spectroscopy analysis:}

The IR spectra of RC and a physical mixture containing $\mathrm{RC}$ and excipients (Pluronic F68, lactose, mannitol, sodium starch glycollate, talc, tribasic calcium phosphate, magnesium stearate, and sodium lauryl sulphate) were obtained using FTIR spectrophotometer (Jasco, Japan). The samples were mixed with potassium bromide and compressed to form disks. These disks were scanned from 4000 to $400 \mathrm{~cm}^{-1}$.

\section{Preparation of nanosuspension:}

Nanosuspension was prepared using a high shear homogenization technique ${ }^{[23]}$. During the preparation of nanosuspension, $60 \mathrm{mg}$ of sodium lauryl sulphate and $1200 \mathrm{mg}$ of Pluronic F68 were added to $230 \mathrm{ml}$ of distilled water and sonicated using a probe sonicator (Vibra Sonics, USA) for $5 \mathrm{~min}$, following which $70 \mathrm{ml}$ of water was added. RC (300 mg) was dissolved in $30 \mathrm{ml}$ of acetonitrile and added drop-wise to the aqueous 
solution with stirring at $1000 \mathrm{rpm}$. Finally, the mixture was homogenized using a high speed homogenizer for $30 \mathrm{~min}$ at $20000 \mathrm{rpm}$ to obtain NRC. The NRC was the converted to powder by lyophilization at $-40^{\circ}$ and -1.12 mbar pressure for $72 \mathrm{~h}$ using a lyophiliser (Lyodel, India) $^{[24]}$.

\section{Preparation of solid dispersion:}

The DRC was prepared by fusion method ${ }^{[25]}$. Briefly, Pluronic F68 (4000 mg) and PEG-6000 (4000 mg) were heated at $50^{\circ}$ on a mantle until a molten solution was formed. To the molten solution, RC (1000 mg) was added and triturated vigorously. After cooling to room temperature, the solidified mass was ground, sieved (sieve No.100) and then stored at room temperature.

\section{Angle of repose ( $\theta)$ :}

The angle of repose values of $\mathrm{RC}$ and the powder blends of NRC and DRC were determined by the funnel method (Reposogram $)^{[1]}$. Accurately weighed powder blend was taken in a funnel and the powder was allowed to flow through the funnel freely onto the surface. The experiment was performed until the apex of the heap of the powder touches the tip of the funnel. The diameter of the powder cone was measured and angle of repose was calculated using the following Eqn., $\theta=\tan ^{-1}(\mathrm{~h} / \mathrm{r})$, where, $\mathrm{h}=$ the height of the powder cone and $\mathrm{r}=$ the radius of the powder cone.

\section{Bulk density:}

Loose bulk density (LBD) and tapped bulk density (TBD) of RC and the powder blends of NRC and DRC were determined using a bulk density apparatus (Electrolab, India) ${ }^{[1]}$. Accurately weighed $5 \mathrm{~g}$ of the powdered blend was placed in a $100 \mathrm{ml}$ graduated measuring cylinder and the initial volume was observed. The cylinder was tapped initially 200 times from a distance of $14 \pm 2 \mathrm{~mm}$. The tapped volume ( Va) was measured to the nearest graduated unit. The tapping was repeated additional 200 times. Again the tapped volume was measured to the nearest graduated unit. The same thing was done for powder blends. The LBD and TBD were calculated in gram per millilitre using following formula; LBD is the weight of the powder/ volume of the packing and TBD is the weight of the powder/tapped volume of the packing.

\section{Compressibility index (Carr's index) and Hausner ratio:}

The compressibility index of the powder blends was determined by Carr's compressibility index. Carr's index (\%) can be calculated by using the following Eqn., Carr's index $=[($ TBD-LBD $) \times 100] / T B D$. The Hausner ratio is an indirect method to determine the powder flow property. It was determined using the following Eqn., Hausner ratio=TBD/LBD.

\section{Drug content in NRC and DRC:}

The NRC and DRC (100 mg) were dissolved in $100 \mathrm{ml}$ of distilled water. The amount of drug present in the water was estimated using UV/Vis spectroscopy at $246 \mathrm{~nm}$.

\section{Formulation of tablets:}

The RC tablets were prepared by direct compression ${ }^{[16]}$ and wet granulation methods ${ }^{[17]}$. In total, 5 different batches of RC tablets were prepared by direct compression and wet granulation methods using lyophilised NRC and DRC (Table 1). A sixth batch, F6, comprising marketed tablets was used as a control. For the tablets prepared using direct compression, all the ingredients were passed through sieve no. 40 and dried at $45^{\circ}$. Weighed quantities of drug and excipients were mixed well and the powder blend was compressed on a 10 station rotary punching machine (Rimek, India) using $8 \mathrm{~mm}$ diameter flat faced punches.

For the preparation of tablets using wet granulation technique, accurately weighed powders of either of lyophilised NRC or DRC, lactose monohydrate, microcrystalline cellulose, tribasic calcium phosphate, sodium starch glycolate, and tamarind gum were mixed well and passed through a sieve no. 40. After addition of water, the wet mass was passed through a $9.5 \mathrm{~mm}$ sieve to obtain granules. The granules were dried at $60^{\circ}$ for $1 \mathrm{~h}$ using a drying oven and mixed well for 30 min with magnesium stearate and talc. The granules

\section{TABLE 1: METHODS OF PREPARATION OF VARIOUS BATCHES OF TABLETS}

\begin{tabular}{|c|c|}
\hline $\begin{array}{l}\text { Formulation } \\
\text { Code }\end{array}$ & Details of the formulation \\
\hline F1 & $\begin{array}{c}\text { NRC tablets prepared using wet granulation } \\
\text { technique }\end{array}$ \\
\hline F2 & $\begin{array}{c}\text { NRC tablets prepared using direct } \\
\text { compression technique }\end{array}$ \\
\hline F3 & $\begin{array}{c}\text { DRC tablets prepared using wet granulation } \\
\text { technique }\end{array}$ \\
\hline $\mathrm{F} 4$ & $\begin{array}{c}\text { DRC tablets prepared using direct } \\
\text { compression technique }\end{array}$ \\
\hline F5 & $\begin{array}{c}\text { Control tablets (prepared without using any } \\
\text { technology) }\end{array}$ \\
\hline F6 & Marketed tablet \\
\hline
\end{tabular}

NRC is nanosuspension of rosuvastatin calcium, DRC is solid dispersion of rosuvastatin calcium 
were punched on a Rimek 10 station rotary punching machine using $8 \mathrm{~mm}$ diameter flat faced punches. Control tablets using RC were also prepared without using any technologies for reducing the particles size. The tablets were stored in a tightly closed Borosil bottles with polypropylene screw caps at room temperature in a dark place until further evaluation.

\section{Uniformity of weight of the tablets:}

The test was performed according to Indian Pharmacopeia (IP). Twenty tablets were weighed individually and their average weight was calculated. The percentage deviation was calculated using the following Eqn., average weight=total weight/no. of tablets, percentage deviation=individual weightaverage weight/average weight $\times 100$.

\section{Thickness of the tablets:}

The thickness of tablets was measured using a vernier callipers. Six tablets from each batch were selected and evaluated. The extent to which the thickness of each tablet deviated from $\pm 5 \%$ of the standard value was determined.

\section{Friability testing of the tablets:}

This test was performed according to IP. Friability is the loss of weight of tablet in the container/package, due to removal of fine particles from the surface. This in process quality control test was performed to ensure the ability of tablets to withstand the shocks during processing, handling, transportation, and shipment. Roche friabilator was used to measure the friability of the tablets ${ }^{[8]}$. Ten tablets were weighed collectively and placed in the chamber of the friabilator and rolled at $25 \mathrm{rpm}$ for $4 \mathrm{~min}$. After removal of the fines, the tablets were again weighed collectively. The percent friability was determined using the following Eqn., $\%$ friability $=(\mathrm{W} 1-\mathrm{W} 2) / \mathrm{W} 1 \times 100$, where, $\mathrm{W}_{1}$ is the weight of the tablet before test and $\mathrm{W}_{2}$ is the weight of the tablets after test.

\section{Hardness test:}

Hardness (diametric crushing strength) is a force required to break a tablet across the diameter. The hardness of a tablet is an indication of its strength. The tablet should be stable to mechanical stress during handling and transportation. The degree of hardness varies with the different manufacturers and with the different types of tablets. The hardness was tested using texture analyser (TA.XT.Plus, Stable Micro Systems,
UK). The tablets were placed on the platform and the force required to break the tablets was measured using a quarter inch spherical stainless probe. Ten tablets from each batch were tested and the average of the ten values was found. The force was measured in kilograms per $\mathrm{cm}$ square. The average hardness of the tablets was calculated using the Eqn., average hardness = total hardness of the 10 tablets/no. of tablets.

\section{Disintegration time:}

The disintegration time of the tablet was measured as per IP using a disintegration apparatus ${ }^{[1]}$. Each of the 6 tablets was placed in the six tubes and immersed in water bath maintained at $37^{\circ}$. The time required for the tablets to disintegrate was observed and recorded.

\section{In vitro dissolution studies:}

In vitro drug release of the samples was carried out according to the USP dissolution method ${ }^{[1]}$ (type II dissolution apparatus, paddle type). The dissolution medium ( $900 \mathrm{ml}$ of phosphate buffer at $\mathrm{pH}$ 6.8) was placed in the dissolution basket at a temperature of $37 \pm 0.5^{\circ}$ and $\mathrm{rpm}$ of 50 . One milliliter of sample was withdrawn periodically at every $5,10,20,30,40,50$, and $60 \mathrm{~min}$. At every withdrawal, the dissolution medium was replaced with the same quantity of fresh buffer. The samples were estimated for the concentration of RC using UV/Vis spectroscopy at $246 \mathrm{~nm}$. The cumulative percentage drug release was calculated.

\section{Testing the mucoadhesive property of tamarind gum using texture analyser:}

The mucoadhesive property of the tablets prepared with tamarind gum as a binder was evaluated in vitro on goat stomach mucosa using texture analyser. Mucoadhesive rig (A/MUC) and a $10 \mathrm{~mm}$ cylindrical probe were used for the study and the instrument was equipped with a $5 \mathrm{~kg}$ load cell. Initially, the mucosal membrane was placed in the centre of the A/MUC and maintained at $37 \pm 1^{\circ}$ in $200 \mathrm{ml} \mathrm{pH} 7.4$ phosphate buffer saline. The tablet was attached underside the $10 \mathrm{~mm}$ cylindrical probe using a double sided tape and immersed in the medium. During the tests, a trigger force of $0.05 \mathrm{~N}$ was applied and the probe was lowered onto the surface of the mucoadhesive membrane with a constant speed of $0.5 \mathrm{~mm} / \mathrm{s}$. The tablet was allowed to remain in contact with the mucoadhesive membrane for $300 \mathrm{~s}$ under an initial contact force $(1 \mathrm{~N})$. After the contact time, the maximum detachment force ( $\mathrm{F} \max$ ) required to separate the probe from the mucous membrane was 
recorded directly with the help of texture exponent 32 software. Each experiment was carried out 3 times.

\section{Statistical analysis:}

Statistical analysis was performed using GraphPad Prism version 6.0. All the mean values were presented with their standard deviations (mean \pm SD). Statistically significant differences were determined using One-way ANOVA and $p$ value $<0.05$ was considered statistically significant.

\section{RESULTS AND DISCUSSION}

The current research work was performed to enhance the dissolution of $\mathrm{RC}$ by preparing tablets containing nanosuspension and solid dispersion using tamarind gum as binder. Tamarind seed polysaccharide is a galactoxyloglucan isolated from the seed kernel of Tamarindus indica. There are also reports suggesting its ability to lower cholesterol, which may show synergistic effect when used with RC for treating hyperlipedemia. The extracted tamarind gum shows major peaks at $91.10^{\circ}$ indicated endothermic peak and $330.58^{\circ}$ indicated exothermic peak (fig. 1). The obtained results indicated that extracted tamarind gum shown similar peaks like reported studies ${ }^{[26]}$. It confirms extracted tamarind gum was pure and suitable for formulation development. The nanosuspension and DRC was prepared by high shear homogenisation and melt fusion techniques, respectively. Finally, tablets of these powders were prepared by direct compression and wet granulation technique using tamarind gum $(\sim 3 \%)$ as the binder. Preliminary trials were performed to optimize the amount of tamarind gum required.

In this study, initially, the presence of interactions between RC and the excipients used in the formulations like Pluronic F68, lactose, mannitol, sodium starch glycollate, talc, tribasic calcium phosphate, magnesium stearate, and sodium lauryl sulphate were tested using infrared spectroscopy. In the spectra corresponding to RC, wave numbers were observed at 965.40, 1155.40, 12291563.36 , and $1605.79 \mathrm{~cm}^{-1}$ which corresponded to $\mathrm{C}-\mathrm{C}$ stretching, C-O stretching, $\mathrm{C}-\mathrm{N}$ stretching/C-O stretching, $\mathrm{C}=\mathrm{C}$ ring stretching and asymmetric $\mathrm{C}-\mathrm{O}$ stretching, respectively (fig. 2). The infrared spectra of the physical mixture of $\mathrm{RC}$ and the excipients indicate the presence of drug-polymer-specific interactions (fig. 2). These results represent the miscibility between RC and the excipients at the molecular level. Additionally, mild changes in the wave number of $\mathrm{RC}$ with respect to $\mathrm{OH}$ stretching indicate formation of hydrogen bonding with RC. Final optimized NRC was prepared based on the preliminary trials by varying the amount of sodium lauryl sulphate and Pluronic F 68, speed of homogenisation and duration of homogenisation. This was done by homogenising the suspension at a speed of $20000 \mathrm{rpm}$ for $30 \mathrm{~min}$. The particle size of the nanosuspension, measured using Malvern particle size analyser was found to be $453.3 \pm 23.6 \mathrm{~nm}$. Usage of high speed and surfactantfacilitated reduction lead to particle size of nanometric range. The morphology of the nanosuspension, as observed under scanning electron microscopy, indicated needle shaped structures (fig. 3). This is due to the formation of nanocrystals of RC, which would enhance

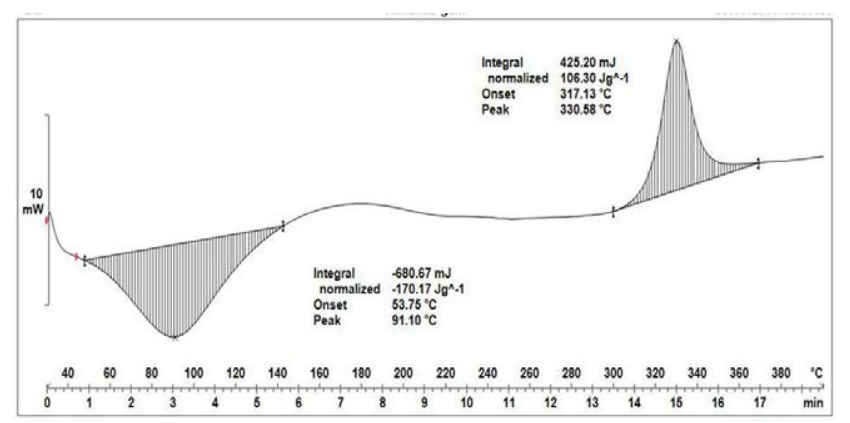

Fig. 1: DSC curve of tamarind gum
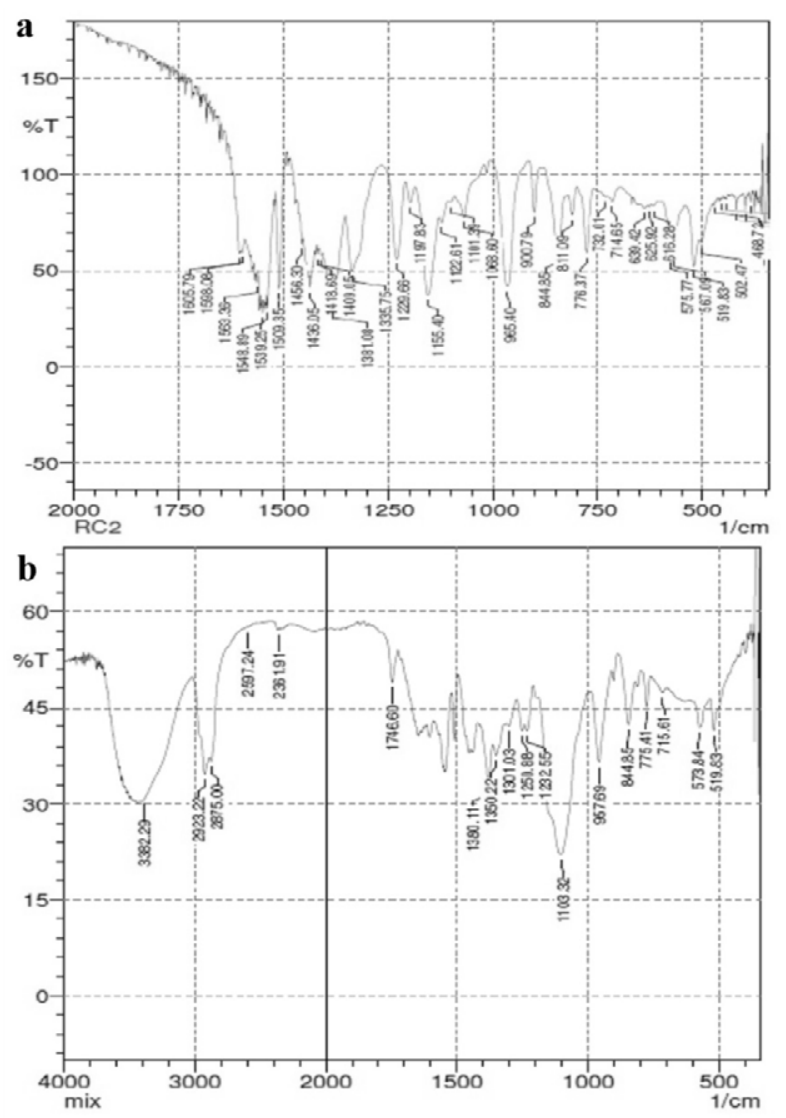

Fig. 2: Infrared spectra of RC and physical mixture Infrared spectra of a. rosuvastatin calcium (RC) and b. physical mixture 
the solubility in aqueous medium ${ }^{[26]}$. The zeta potential of the NRC was found to be $-6.01 \pm 1.25 \mathrm{mV}$. A neutral zeta potential was observed due to the usage of Pluronic F68, a non-ionic surfactant, during the preparation of nanosuspension ${ }^{[27]}$. Finally, NRC was lyophilised into a fine powder. Alternatively, for the preparation of the solid dispersion, $4 \mathrm{~g}$ of Pluronic F68 and $4 \mathrm{~g}$ of PEG was chosen and melted, to which $1 \mathrm{~g}$ of RC was added. The results of drug content study showed that $20 \mathrm{mg}$ of $\mathrm{RC}$ was present in $390 \mathrm{mg}$ of NRC powder and $470 \mathrm{mg}$ of DRC powder.

Swelling test confirmed the presence of gum. Molish test, ruthenium test and iodide test additionally confirmed that the isolated gum had mucilage, polysaccharides and carbohydrates respectively, which confirmed the results obtained from other studies ${ }^{[19,20]}$.

The powder blends of RNC and DRC, along with the excipients (Table 2), were prepared by mixing and further evaluated for various pre-compression parameters. Lactose monohydrate was used as filler in the preparation of direct compression and wet granulation tablets as it had uniform particle size distribution and good flow characteristics. Tribasic calcium phosphate was used a binder and filler. Sodium starch glycolate was used as a disintegrant. Microcrystalline cellulose was used to improve the flow, impart hardness to the tablet, and also to facilitate disintegration. Magnesium stearate was added as a lubricant to the tablets. Talc was

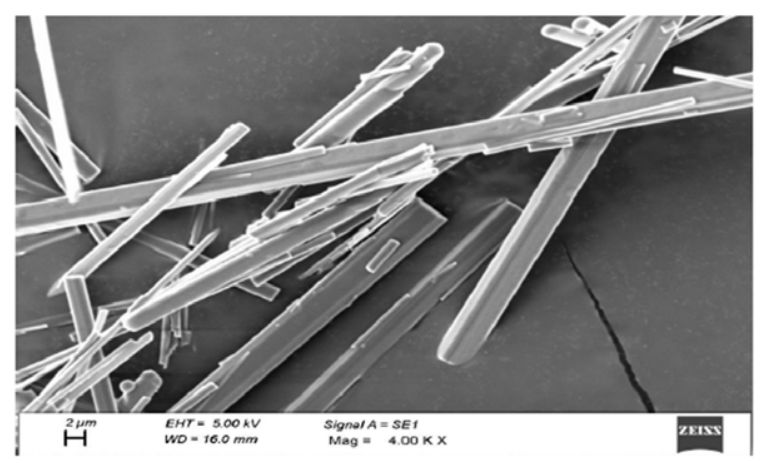

Fig. 3: Scanning electron micrograph of NRC added to enhance the flow property of the powder. The ability of tamarind gum to act as a binder was tested. The powders were thoroughly mixed during blending.

The flow property of different blends of powders was measured before the preparation of tablets by finding out angle of repose, bulk density, tap density, compressibility index and Hausner ratio. The angle of repose for RNC powder mixture and DRC powder mixture was found to be $29^{\circ}$ and $25^{\circ}$, which indicated that the powders had good flow property (Table 3 ). Among the powder mixtures tested, NRC containing powder mixture showed good flow over the powder mixture containing DRC. The smaller particle and presence of surfactant coating across RC in NRC powder mixture could have enhanced the flow of the powder. Hence, nanosuspensions may be a better choice over solid dispersion if a good flow property is expected.

Inter particulate interactions among the powders also influence the bulk properties of powder. A comparison of the bulk density and tapped density provide information about the relative importance of these interactions in a given powder. Often, such comparison is used as an index of the ability of the powder to flow. The bulk density of NRC powder mixture and DRC powder mixture was found to be $0.493 \pm 0.006$ and $0.463 \pm 0.008$, respectively; the tapped density of NRC and DRC was in the range of $0.657 \pm 0.016$ and $0.546 \pm 0.08 \mathrm{~g} / \mathrm{ml}$, which indicated that the powders were not bulky. NRC showed higher values than DRC. The Carr's index of the powder mixtures of NRC and DRC was found to be in the range of $25.00 \pm 0.97$ and $16.66 \pm 1.14$. The Hausner ratio for powder mixtures of NRC and DRC was found to be in the range of $1.33 \pm 0.06$ to $1.21 \pm 0.015$, indicating good compressibility index for the powder blend (Table 3). The physical properties of powder blends (NRC and DRC) showed significant differences in the parameters $(\mathrm{p}<0.05)$.

Various quality parameter tests like weight variation, thickness, hardness, friability, disintegration, and

TABLE 2: COMPOSITION OF THE TABLETS

\begin{tabular}{lccccc}
\hline Ingredients & \multicolumn{5}{c}{ Formulation code } \\
\cline { 2 - 6 } & F1 & F2 & F3 & F4 & F5 \\
\hline Nanosuspension/solid dispersion powder & 110 & 110 & 190 & 190 & 20 \\
equivalent to 20 mg & 50 & 50 & 50 & 50 & 50 \\
Lactose monohydrate $(\mathrm{mg})$ & 28.9 & 28.9 & 28.9 & 28.9 & 28.9 \\
Tribasic calcium phosphate (mg) & 3.1 & 3.1 & 3.1 & 3.1 & 3.1 \\
Sodium starch glycolate (mg) & 15 & 15 & 15 & 15 & 15 \\
Tamarind gum (mg) & 3 & 3 & 3 & 3 & 3 \\
Magnesium stearate (mg) & 6 & 6 & 6 & 6 & 6 \\
Talc (mg) & 174 & 174 & 174 & 174 & 174 \\
Microcrystalline cellulose (mg) & & & & & \\
\hline
\end{tabular}


dissolution time were set for all the batches of the manufactured tablets. Weight variation test was performed as per IP with a rationale to ensure that required amount of powder will fill the die uniformly for all the batches. Changes in the weight of tablet would change the amount of drug present in the tablet. Thus, it is necessary for every tablet to have a uniform weight. As per the IP limits, deviation within the permissible limit of $7.5 \%$ is allowed. The $\%$ deviation calculated in the present study indicated values less than $7.5 \%$ of the average weight of the tablet. Hence, all batches comply with the test for weight variation as per IP (Table 4). The average thickness of tablets measured using vernier callipers was in the range of $2.12 \pm 0.015$ to $2.41 \pm 0.051 \mathrm{~mm}$. The friability of all the batches of tablets was found to be less than $1 \%$, indicating that all the batches of tablets were found to pass the test for friability of tablets as per IP (Table 4). The hardness of all batches of tablets was found to be in range of $3.32 \pm 0.31-4.02 \pm 0.37 \mathrm{~kg} / \mathrm{cm}^{2}$ (Table 4). Marketed tablets showed hardness of $3.88 \pm 0.53 \mathrm{~kg} / \mathrm{cm}^{2}$. All the values passed the test for hardness.

The disintegration test was performed as per IP. The results of the disintegration time in (Table 4) indicated that the time taken for different batches of tablets was in the range of $8 \pm 1$ to $12 \pm 2 \mathrm{~min}$. All the tablets disintegrated in less than $15 \mathrm{~min}$, thereby meeting the criteria as stated in IP. Among the different batches of tablets prepared, the control tablets had highest disintegration time possibly because of stronger binding forces between the excipients. Formulation F2 and F4 prepared using direct compression technique were found to have similar disintegration time of $8 \pm 1 \mathrm{~s}$ similar to marketed tablets (F6). Tablets prepared using direct compression showed lower disintegration times when compared to the tablets prepared using wet granulation techniques. NRC or DRC in the direct compressed tablets could dissolve rapidly with the aqueous medium in the gastrointestinal tract, enhance the absorption window, and consequently improve the oral bioavailability of RC.

The results of the in vitro release studies indicated that formulations $\mathrm{F} 2$ and $\mathrm{F} 4$ showed maximum drug release by the end of $60 \mathrm{~min}$ (fig. 4). In vitro drug release of RC from NRC tablets prepared by direct compression technique (F2) was nearly $50 \%$ in $10 \mathrm{~min}$ and $98 \%$ at the end of $60 \mathrm{~min}$. The drug release was significantly higher $(<0.05)$ in $\mathrm{F} 2$ formulation when compared to F1. But the release pattern of RC from NRC tablets prepared by wet granulation technique (F1) showed only $15 \%$ in the first $10 \mathrm{~min}$ and $92 \%$ at the end of $60 \mathrm{~min}$ against the control tablets (F5), F5 which showed only $5 \%$ release in $10 \mathrm{~min}$ and $25 \%$ at the end of $60 \mathrm{~min}$. Due to the usage of tamarind gum in the preparation of tablets, the release of RC from the tablets prepared by wet granulation could have hindered.

The results of the in vitro release study also indicated that the tablets prepared by wet granulation technique, using DRC (F3) showed only $6 \%$ release in the first $5 \mathrm{~min}$ and $88 \%$ at the end of $60 \mathrm{~min}$. The drug release of $\mathrm{RC}$ from DRC tablets prepared by direct compression technique (F4) was nearly $50 \%$ in $10 \mathrm{~min}$ and $96 \%$ at the end of $60 \mathrm{~min}$. The drug release was significantly higher $(<0.0001)$ in $\mathrm{F} 4$ formulation when compared to F3. This confirms that conversion of RC to NRC and DRC improved the dissolution of RC into the aqueous environment. This also indicated that direct compression could be a better technique to obtain faster release. The release pattern in this study confirmed that apart from tamarind gum acting as binder, it also enhanced the release of RC from NRC and DRC tablets compared

TABLE 3: PHYSICAL PROPERTIES OF DIFFERENT POWDER BLENDS

\begin{tabular}{lccccc}
\hline Formulation & $\begin{array}{c}\text { Angle of repose } \\
(\text { mean } \pm \text { SD) }\end{array}$ & $\begin{array}{c}\text { Bulk density }(g / m l) \\
(\text { mean } \pm \text { SD) }\end{array}$ & $\begin{array}{c}\text { Tap density }(g / m l) \\
(\text { mean } \pm S D)\end{array}$ & $\begin{array}{c}\text { Compressibility index } \\
(\text { mean } \pm S D)\end{array}$ & $\begin{array}{c}\text { Hausner ratio } \\
(m e a n \pm S D)\end{array}$ \\
\hline NRC & $29^{\circ} 40^{\prime \prime} \pm 43^{\prime \prime}$ & $0.493 \pm 0.006$ & $0.657 \pm 0.016$ & $25.00 \pm 0.97$ & $1.33 \pm 0.06$ \\
DRC & $25^{\circ} 49^{\prime \prime} \pm 31^{\prime \prime}$ & $0.463 \pm 0.008$ & $0.546 \pm 0.08$ & $16.66 \pm 1.14$ & $1.21 \pm 0.015$ \\
\hline
\end{tabular}

SD is standard deviation for $n=3$ observations, $p<0.05$, one-way ANOVA

TABLE 4: QUALITY CONTROL PARAMETERS FOR DIFFERENT FORMULATIONS

\begin{tabular}{lccccc}
\hline Formulation & $\begin{array}{c}\text { Weight variation } \\
(\mathbf{m g}, \text { mean } \pm \text { SD) }\end{array}$ & $\begin{array}{c}\text { Friability } \\
(\%, \text { mean } \pm \text { SD })\end{array}$ & $\begin{array}{c}\text { Thickness } \\
(\mathbf{m m}, \text { mean } \pm \text { SD })\end{array}$ & $\begin{array}{c}\text { Hardness } \\
\left(\mathbf{k g} / \mathbf{c m}^{2}, \mathbf{m e a n}_{ \pm} \mathrm{SD}\right)\end{array}$ & $\begin{array}{c}\text { Disintegration } \\
(\mathbf{m i n}, \mathrm{mean} \pm \mathrm{SD})\end{array}$ \\
\hline F1 & $393 \pm 2.4$ & $0.1 \pm 0.03$ & $2.41 \pm 0.05$ & $3.32 \pm 0.31$ & $9 \pm 2$ \\
F2 & $391 \pm 3.1$ & $0.4 \pm 0.14$ & $2.41 \pm 0.05$ & $3.98 \pm 0.38$ & $8 \pm 1$ \\
F3 & $474 \pm 2.5$ & $0.3 \pm 0.08$ & $2.12 \pm 0.02$ & $3.72 \pm 0.19$ & $10 \pm 2$ \\
F4 & $472 \pm 2.2$ & $0.3 \pm 0.09$ & $2.26 \pm 0.01$ & $3.98 \pm 0.38$ & $8 \pm 2$ \\
F5 & $300.5 \pm 3.3$ & $0.3 \pm 0.02$ & $2.39 \pm 0.12$ & $4.02 \pm 0.37$ & $12 \pm 2$ \\
F6 & $150 \pm 1.6$ & $0.3 \pm 0.03$ & $4.10 \pm 0.00$ & $3.88 \pm 0.53$ & $8 \pm 1$ \\
\hline
\end{tabular}

SD is standard deviation for $n=3$ observations 
www.ijpsonline.com

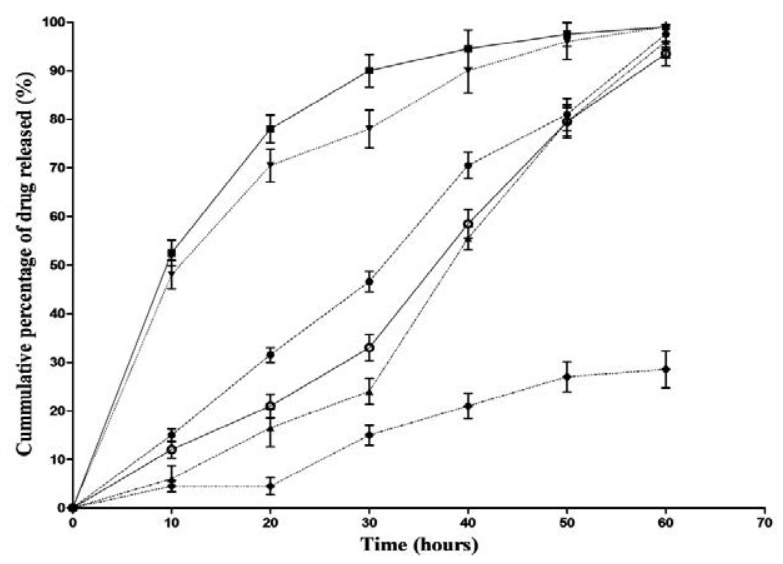

Fig. 4: In vitro release profile of different formulations

SD is standard deviation for $n=3$ observations, (-•-) NRC tablets prepared using wet granulation technique (F1), (- - -) NRC tablets prepared using direct compression technique (F2), $(-\Delta-)$ DRC tablets prepared using wet granulation technique (F3), ( $-\nabla-)$ DRC tablets prepared using direct compression technique (F4), (一- control tablets (F5), (-O-) marketed tablet (F6)

to control and marketed tablets. The enhanced release might be due to the hydrophilic nature of the tamarind gum powder.

NRC and DRC tablets with enhanced dissolution could improve the bioavailability in vivo. Mucoadhesive test was performed on goat stomach for the tablets using texture analyser to investigate the ability of tamarind gum at $3 \%$ to adhere to the mucous membrane. The adhesiveness of the tablet with mucous membrane was measured as force of adhesion. Usage of tamarind gum at $3 \%$ in this study showed that $0.053 \pm 0.007 \mathrm{~N}$ of force was required to pull the tablet from the surface of the mucous membrane and the work of adhesion spent for the removal of the tablet was 0.0008 N.s. These results indicated that tamarind gum at $3 \%$, possessed weak mucoadhesive property. Higher concentration of tamarind gum in the tablets might possibly facilitate formation of stronger bonds between mucin and tamarind gum to enhance the mucoadhesive property.

In the light of the above, considering the factors such as low particle size, high surface area for absorption, lower disintegration time and better dissolution profile, formulation F2, prepared using lyophilised NRC by direct compression method could be considered as the optimum formulation to show enhanced bioavailability. The amount of drug released at the end of $60 \mathrm{~min}$ was found to be 98 and $85 \%$ for F2 and F6, respectively. Significant release $(<0.05)$ was observed in F2 when compared to F6.

Tablets prepared using nanosuspension and solid dispersion showed better dissolution profile when compared to the control tablets. The results of in vitro dissolution study highlighted the ability of $3 \%$ tamarind gum to act as binder in the preparation of tablets. These results further indicated that preparation of tablets for BCS class II drugs using nanosuspension and solid dispersion would be good methods to enhance the dissolution and consequently the bioavailability of the drugs. However, more pharmacokinetic studies are needed to support the claim.

\section{Acknowledgements:}

The authors would like to thank PSG College of Pharmacy for providing all the required facilities for performing the work.

\section{Conflict of interest:}

The authors do not report any conflict of interest pertaining to this work.

\section{REFERENCES}

1. Sankar V, Ramakrishna B, Devi PS, Karthik S. Oral disintegration tablets of stavudine for HIV management: A new technological approach. Indian J Pharm Sci 2012;74(6):556.

2. Modi A, Tayade P. Enhancement of dissolution profile by solid dispersion (kneading) technique. AAPS PharmSciTech 2006;7(3):E87.

3. Williams HD, Trevaskis NL, Charman SA, Shanker RM, Charman WN, Pouton CW, et al. Strategies to Address Low Drug Solubility in Discovery and Development. Pharmacol Rev 2013;65(1):315-499.

4. Hussain Z, Thu HE, Ng SF, Khan S, Katas H. Nanoencapsulation, an efficient and promising approach to maximize wound healing efficacy of curcumin: A review of new trends and stateof-the-art. Colloids Surf B Biointerfaces 2017;150:223-41.

5. Khadka P, Ro J, Kim H, Kim I, Kim JT, Kim H, et al. Pharmaceutical particle technologies: An approach to improve drug solubility, dissolution and bioavailability. Asian J Pharm Sci 2014;9(6):304-16.

6. Ghosh S, Roy T. Nanoparticulate drug-delivery systems: Lymphatic uptake and its gastrointestinal applications. J Appl Pharm Sci 2014;4(6):123-30.

7. Balakumar K, Raghavan CV, Selvan NT, Prasad RH, Abdu S. Self nanoemulsifying drug delivery system (SNEDDS) of Rosuvastatin calcium: Design, formulation, bioavailability and pharmacokinetic evaluation. Colloids Surf B Biointerfaces 2013a;112:337-43.

8. Kapure VJ, Pande VV, Deshmukh PK. Dissolution Enhancement of Rosuvastatin Calcium by Liquisolid Compact Technique. J Pharm 2013;2013:1-9.

9. Dudhipala N, Veerabrahma K. Improved anti-hyperlipidemic activity of Rosuvastatin Calcium via lipid nanoparticles: Pharmacokinetic and pharmacodynamic evaluation. Eur J Pharm Biopharm 2017;110:47-57.

10. Beg S, Raza K, Kumar R, Chadha R, Katare OP, Singh B. Improved intestinal lymphatic drug targeting via phospholipid complex-loaded nanolipospheres of rosuvastatin calcium. RSC Adv 2016;6(10):8173-87. 
11. Beg S, Jain S, Kushwah V, Bhatti GK, Sandhu PS, Katare $\mathrm{O}$, et al. Novel surface-engineered solid lipid nanoparticles of rosuvastatin calcium for low-density lipoproteinreceptor targeting: a Quality by Design-driven perspective. Nanomedicine 2017;12(4):333-56.

12. Rizwanullah M, Amin S, Ahmad J. Improved pharmacokinetics and antihyperlipidemic efficacy of rosuvastatin-loaded nanostructured lipid carriers. J Drug Target 2017;25(1):58-74.

13. Teixeira CCC, Mendonça LM, Bergamaschi MM, Queiroz RHC, Souza GEP, Antunes LMG, et al. Microparticles Containing Curcumin Solid Dispersion: Stability, Bioavailability and Anti-Inflammatory Activity. AAPS PharmSciTech 2016;17(2):252-61.

14. Huang Y, Dai WG. Fundamental aspects of solid dispersion technology for poorly soluble drugs. Acta Pharm Sin B 2014;4(1):18-25.

15. Kalepu S, Nekkanti V. Insoluble drug delivery strategies: review of recent advances and business prospects. Acta Pharm Sin B 2015;5(5):442-53.

16. Zhao Y, Xin T, Ye T, Yang X, Pan W. Solid dispersion in the development of a nimodipine delayed-release tablet formulation. Asian J Pharm Sci 2014;(1):35-41.

17. Daraghmeh N, Rashid I, Al Omari MMH, Leharne SA, Chowdhry BZ, Badwan A. Preparation and Characterization of a Novel Co-processed Excipient of Chitin and Crystalline Mannitol. AAPS PharmSciTech 2010;11(4):1558-71.

18. Ozturk B, Argin S, Ozilgen M, McClements DJ. Formation and stabilization of nanoemulsion-based vitamin $\mathrm{E}$ delivery systems using natural biopolymers: Whey protein isolate and gum arabic. Food Chem 2015;188:256-63.

19. Mohamed BEMH. Physicochemical Properties of Tamarind (Tamarindus indica) Seed Polysaccharides. J Food Process Technol 2015;06(06):201.
20. Shaw GS, Uvanesh K, Gautham SN, Singh V, Pramanik K, Banerjee I, et al. Development and characterization of gelatintamarind gum/carboxymethyl tamarind gum based phaseseparated hydrogels: a comparative study. Des Monomers Polym 2015;18(5):434-50.

21. Kumar CS, Bhattacharya S. Tamarind Seed: Properties, Processing and Utilization. Crit Rev Food Sci Nutr 2008;48(1):1-20.

22. Newton AMJ, Indana VL, Kumar J. Chronotherapeutic drug delivery of Tamarind gum, Chitosan and Okra gum controlled release colon targeted directly compressed Propranolol $\mathrm{HCl}$ matrix tablets and in-vitro evaluation. Int J Biol Macromol 2015;79:290-9.

23. Anton N, Benoit JP, Saulnier P. Design and production of nanoparticles formulated from nano-emulsion templates-A review. J Control Release 2008;128:185-99.

24. Siram K, Chellan VR, Natarajan T, Krishnamoorthy B, Mohamed Ebrahim HR, Karanam V, et al. Solid lipid nanoparticles of diethylcarbamazine citrate for enhanced delivery to the lymphatics: in vitro and in vivo evaluation. Expert Opin Drug Deliv 2014;11(9):1351-65.

25. Greenhalgh DJ, Williams AC, Timmins P, York P. Solubility parameters as predictors of miscibility in solid dispersions. $\mathrm{J}$ Pharm Sci 1999;88(11):1182-90.

26. Dev D, Rehal DK, Prasad DN. Preparation and evaluation of modified tamarind seed gum as a novel superdisintegrant. J Drug Deliv Ther 2018;8(5):372-7.

27. Guo R, Lan Y, Xue W, Cheng B, Zhang Y, Wang C, et al. Collagen-cellulose nanocrystal scaffolds containing curcuminloaded microspheres on infected full-thickness burns repair. J Tissue Eng Regen Med 2017;11(12):3544-55. 